\title{
Reflexiones en torno al patrimonio arqueológico
}

\section{Rosa Fung Pineda}

Quienes nacimos y residimos aquí, y nos consideramos parte de una tradición cultural que todavía mantiene su vigencia a través de sociedades vitales con sus lenguas, instrumentos y costumbres, creemos que la práctica de la disciplina arqueológica es algo más que una mera recopilación de datos. Esa preocupación abarca la integridad del patrimonio histórico cultural, cuya fuente de conocimientos nos permite entender nuestra realidad, es decir, la razón de ser como país, inteligencia, individuos o nación. Se trata, precisamente, de aquella identidad de la que tanto se habla y poco se reconoce, asume y defiende. De suerte que en nuestra trayectoria académica y profesional hemos insistido en el trabajo metódico y cuidadoşo de las excavaciones arqueológicas para recuperar los testimonios, tratando de preservar el contexto primario de los monumentos, con el objetivo de que las futuras generaciones, al contemplarlos y relacionarlos, debatan, reflexionen y se deleiten al confrontarlos a la luz de nuevos conceptos e interpretaciones, apoyados por los avances de la

\footnotetext{
'Discurso, pronunciado por la autora al momento de ser distinguida con el tútulo de Profesora Emérita, Universidad Nacional Mayor de San Marcos, Lima, Perú.
}

ciencia y la tecnología.

Así, persuadidos por estos principios que trascienden las voluntades individuales e ingresan en la jurisdicción del Estado, decidimos intervenir en las sucesivas comisiones nacionales del Patronato Nacional de Arqueología, creadas para cautelar la integridad del legado arqueológico. Una de las mayores frustraciones de esa experiencia ha sido comprobar que la destrucción de los monumentos contó muchas veces con la anuencia, manifiesta o escondida, de organismos y funcionarios gubernamentales.

Enfrentarse al poder autoritario significa correr los riesgos de sus veleidades políticas. Quienes han pasado por trances similares saben que son situaciones abusivas y reprobables, que de un modo u otro afectan la actividad y el desempeño idóneo de los arqueólogos. Porque no obstante la magnitud, riqueza y complejidad de nuestros bienes patrimoniales arqueológicos, los especialistas locales tenemos limitado el acceso a los puestos de trabajo en las instituciones estatales y debemos disputarlos, para colmo, con gente de otras profesiones $u$ oficios 
vinculada a los gobiernos alternos, a la cual no le interesa el quehacer técnico-científico de la disciplina. Este hecho produce frustraciones en la esfera docente, al comprobarse, por ejemplo, que el encargado de turno de un museo estatal no toma en cuenta las recomendaciones del personal capacitado, los técnicos, quienes son, además, sus subalternos. En aras de un exclusivo efectismo museográfico expositivo, embaucador y, al mismo tiempo, destructor, los objetos se manejan inadecuadamente, sin ningún escrúpulo, y no como auténticos documentos históricos.

Ante la crisis de la arqueología peruana, reflejada en la depredación constante de nuestra herencia cultural prehispánica y la notoria falta de cuadros técnico-profesionales nacionales para manejarla y conservarla, planteamos en un documento la necesidad perentoria de adiestrar a los arqueólogos y otros profesionales afines en la apropiada administración del patrimonio arqueológico. La idea es instituir una especie de escuela de graduados equivalente a la aduanera, cuyo funcionamiento no debe considerarse más importante que la administración del patrimonio arqueológico, si tenemos en cuenta que este rico acervo representa un inestimable recurso propio, insustituible y no renovable de la Nación.

Proponemos que el adiestramiento práctico en la administración del patrimonio arqueológico se efectúe en dos planos diferenciados pero relacionados. En uno se ubican los sitios arqueológicos, que exponen el acondicionamiento del espacio geográfico por las antiguas poblaciones. Una configuración territorial agreste, dotada de una "heterogeneidad fisiográfica y biológica casi increíble" (Tossi 1960:1), que el poblador, durante una larga y continua trayectoria de unos quince mil años o más, logró adaptar para vivir en forma equilibrada con su medio. Este proceso histórico convirtió al Perú, junto con México, en uno de los dos únicos núcleos del continente americano donde brotaron precozmente civilizaciones prístinas y en uno de los más grandes e importantes centros originarios de cultivos del mundo.

Por consiguiente, el enfoque propuesto para el primer plano abarca dos realidades estrechamente vinculadas: el contexto sociocultural y el espacio geográfico.
La falta de conocimientos, así como la visión simplista y fragmentaria que los pobladores tienen de las dos realidades, contribuye a degradar, depredar y, por último, arrasar los recursos naturales y los valores tradicionales andinos.

Los estudios y esfuerzos de un grupo de profesionales por rescatar y revalorar las creaciones ancestrales, representadas por los sistemas agrotecnológicos tradicionales andinos, llamados también "técnicas conservacionistas nativas", "reliquias arqueológicas" y "agrotecnologías prehispánicas", son ejemplos del manejo de las relaciones entre el medio natural, la organización social de la producción y las herramientas de trabajo.

La experiencia obtenida en esos proyectos servirían para enseñar a diseñar programas de recuperación y revaloración del patrimonio arqueológico, incorporado a la preservación del espacio y sus recursos, que incluyen al poblador y su medio ambiente natural y sociocultural. Creemos que la única manera de que la protección y la defensa de los monumentos resulten procedimientos de interés social efectivos, sostenidos y multiplicadores es mediante la apropiación y participación consciente de las comunidades locales y sus organismos de gobierno.

Los pueblos, conscientes de lo que hacen y por qué, deben proteger y defender sus tesoros culturales nacionales. Arequipa, por ejemplo, tiene el derecho de reclamar por la Doncella de Ampato. $Y$ todos los pueblos peruanos unidos deberían apoyar su pedido. Por eso preguntamos: ¿cuántas veces han venido al Perú, en reciprocidad, los tesoros culturales nacionales de otros países? Los nuestros salen a cada momento, con la venia gubernamental, para beneficiar a organizaciones empresariales privadas, lo cual es indignante.

Hace un tiempo se presentó en el Museo de la Nación una muestra de los tesoros culturales nacionales de China un centro de civilización igual que el Perú, en la cual se exhibieron excelentes réplicas. A la Princesa China de jade, delicada, aunque no tan frágil como la Doncella de Ampato, difícilmente se le extrae de su lugar de origen, donde es protegida con 
sumo celo y cuidado. Perdería ese especial encanto. Ella forma parte indisoluble del paisaje social y natural que la rodea, adonde acuden sus admiradores chinos y extranjeros. Estamos seguros de que el pueblo chino y sus autoridades no permitirian que la Princesa se alejara por catorce meses o más, como sucede con la Doncella de Ampato, trasladada de una ciudad a otra del Japón, junto con su sagrado ajuar funerario.

\section{¿Qué nos falta para cuidar nuestros tesoros arqueológicos nacionales con el mismo sentido patriótico?}

En cuanto a la ubicación de los sitios arqueológicos, este proceso se inicia con la elaboración de un catastro completo de los monumentos, requisito indispensable para establecer las prioridades y proyecciones de estudio, protección, defensa, revaloración y rescate. De contar con esos catastros, el Instituto Nacional de Cultura protegería y defendería de manera efectiva la integridad del patrimonio arqueológico, expuesto ampliamente a la expansión territorial de grandes intereses económicos privados, en un circuito que comprende a empresas contratadas por compañías explotadoras de bienes nacionales para calcular el llamado "impacto ambiental" de sus operaciones expansivas devastadoras. Las empresas que evalúan el impacto ambiental contratan, a su vez, los servicios de los arqueólogos y sus asistentes, a quienes exigen la rápida evacuación de los informes pertinentes, a fin de que el Instituto Nacional de Cultura dé también apresuradamente su visto bueno.

En consecuencia, predomina la improvisación y son frecuentes los casos en que se unen la incompetencia y la ausencia de ética. Para contrarrestar a esta última no hay, lamentablemente, enseñanza que valga.

La globalización de la economía es tal que no nos extrañaría que se pretenda privatizar no sólo la administración de los monumentos sino también la de todo el patrimonio arqueológico. La intervención de las empresas que evalúan el impacto ambiental hace valedera esta suposición. Un arqueólogo recién egresado, contratado por las mencionadas empresas, percibe una remuneración equiparable a la que gana en doce meses o quizás más un arqueólogo con varios años de servicio en el Instituto Nacional de Cultura. Aquí comparamos sueldos y no la solvencia profesional.

Con los procedimientos actuales se arrasan, a gran escala, oficialmente los sitios arqueológicos; muchos de ellos ni siquiera son reconocidos. Al parecer, en los convenios con las empresas privadas no se incluyen los programas de rescate. Nunca antes el panorama de la arqueología peruana fue tan sombrío.

En búsqueda de una tutela efectiva $y$ conscientes de la responsabilidad que nos corresponde en la práctica de nuestra profesión, denunciamos los hechos para demandar: ¿con qué evidencias reconstruiremos y proyectaremos a la comunidad la historia auténtica y cabal de la Nación peruana, desde sus lejanos comienzos?, ¿ante esta destrucción acelerada del patrimonio arqueológico será posible que lleguemos a conocer, explicar y divulgar la extraordinaria y aleccionadora complejidad del desarrollo de las primigenias sociedades andinas, comprometiendo procesos socioculturales de cambios, reformas, detenimientos, avances y retrocesos que originaron cursos progresivos paralelos desiguales en contacto al combinarse entre sí; la existencia de movimientos migratorios, asentamientos y organizaciones en las relaciones de producción; los intercambios y adquisiciones complementarias de recursos y bienes santuarios; las expansiones y retraimientos territoriales que configuraron las sucesivas diversificaciones y unificaciones regionales, hasta la última del Tahuantinsuyo, cortada por la invasión colonial española? Estos procesos históricos, apenas vislumbrados en sus múltiples interacciones, con efectos $e$ intensidades diferentes, condujeron a la aparición de manifestaciones culturales admiradas por el mundo moderno: la diversidad sobresaliente de plantas oriundas cultivadas; las construcciones de centros ceremoniales con grandiosos edificios públicos; los asentamientos urbanos extensos; los notables sistemas de regadío, andenerías agrícolas y redes viales y la elaboración de obras artísticas en tejidos, arcilla, madera, piedras, huesos, conchas y metales. 
Otro plano de la propuesta se refiere al adiestramiento en la gestión y manejo de nuestro legado arqueológico en los museos.

En el Perú, las disposiciones legales establecen que el patrimonio arqueológico transportable recuperado mediante excavaciones y prospecciones sistemáticas, adquisiciones, donaciones y decomisos queda depositado bajo custodia en los museos estatales. La función de éstos, como la de los museos que resguardan bienes culturales, es preservarlos para conocimiento y enseñanza de las generaciones presentes y futuras. Para tal fin deben disponer de infraestructura apropiada, presupuestos operativos y personal calificado. El Estado y la colectividad tienen, pues, el compromiso ineludible y permanente de vigilar y garantizar su funcionamiento en condiciones adecuadas.

La tarea de preservación en los museos es amplia y compleja. Consiste en tomar medidas y emprender acciones para determinar y controlar los riesgos que corren las colecciones al depositarlas o almacenarlas, exhibirlas o transportarlas. Los daños, calificados desde menores, reparables, hasta pérdidas totales, pueden ocurrir gradualmente, a corto o largo plazo o repentinamente. De modo que para preservar el patrimonio arqueológico en los museos se requiere de personal competente en conservación y gestión, según las situaciones y los factores de deterioro que comprometen a cada objeto o artefacto en particular.

Ese manejo concierne a la integridad física de las colecciones, pero existe otro, también fundamental, que incumbe a la integridad de sus valores históricos, sustentado en la documentación que debe acompañarlas: las cédulas de identificación y los informes sobre las circunstancias de los hallazgos y todas aquellas razones por las que ingresaron y permanecen en el museo.

Las definiciones conceptuales proporcionadas por los Planes de acción en la administración de las colecciones de la Smithsonian Institution sirven para ilustrarnos sobre cuán importante es prestar atención al valor de la documentación:
"La colección de un museo incluye tanto la colección física como su documentación relacionada, llamada algunas veces colección intelectual. Una documentación precisa, completa y oportuna acrecienta las oportunidades de investigación y perfecciona el acceso y el cuidado permanente de la colección. El valor documental de la colección de un museo es un criterio principal de su excelencia. Por lo tanto, los registros de las colecciones deben ser del más alto nivel en cuanto a exactitud y entereza."

El descuido en el manejo del patrimonio arqueológico en el Museo Nacional de Antropología y Arqueología se hizo evidente a raíz de las sustracciones de algunos de los famosos mantos bordados de Paracas. Aunque parezca inverosímil, el robo no fue descubierto por la inspección periódica del personal encargado, que debía confrontar regularmente las colecciones con la correspondiente documentación básica actualizada (registros, inventarios y catálogos), en especial porque se trataba de la colección textil más importante y singular que custodia el museo, ya que procede de las excavaciones arqueológicas dirigidas por el doctor Julio C. Tello.

La sustracción se hizo pública recién cuando estudiosos norteamericanos que habian investigado $y$ fotografiado esos mantos en el museo informaron que los valiosos tejidos se hallaban en el extranjero. Al urgirse al museo que demostrara la pertenencia de estos bienes, a fin de que se los devuelvan, se comprobó que la documentación probatoria indispensable se reducía a inventarios no verificables y registros desordenados, confusos e incoherentes.

Mientras estudiábamos la cerámica de Kuntur Wasi en el Museo Nacional de Antropología y Arqueología se nos encomendó elaborar y coordinar un inventario de las colecciones de su departamento textil. De esa tarea se encargó el personal técnico entrenado en la conservación de tejidos mediante los cursos taller organizados por el entonces Proyecto Regional de Patrimonio Cultural y Desarrollo de la Unesco. Cuando el inventario se hallaba muy avanzado en un tiempo relativamente corto, tal como se previó durante las discusiones, el análisis y la elaboración de la ficha, nos ordenaron suspenderlo. No se ofreció ninguna explicación, 
por lo que presumimos que querían evitar que se descubrieran e impidieran, más adelante, otras irregularidades que convenían a intereses ajenos a la institución. En circunstancias similares dolorosas en el ámbito personal fui destituida intempestivamente de la dirección del Museo Arqueológico de la Universidad Nacional Mayor de San Marcos, justo cuando elaboraba el inventario y los registros de sus colecciones, destinados a encaminar las gestiones ligadas, además, a la formación académica profesional de arqueólogos en el marco de las ciencias históricosociales.

Los dos casos reseñados muestran cómo las respectivas autoridades no se interesan por brindar una administración eficiente y oportuna que salvaguarde la integridad del patrimonio arqueológico. Examinemos el primero, cosiderando la cantidad y la calidad de las colecciones allí custodiadas.

Debido a la importancia del Museo Nacional de Antropología y Arqueología, su director gozaba de una posición prestigiosa, respetada y estable porque se le exigía prestancia profesional académica, científica y técnica. Eso terminó en 1979, cuando por decreto de gobierno la designación al cargo fue política, es decir, se convirtió en un puesto de confianza. Hoy tiene un rango aún menor, pero ha crecido en cuanto a dependencia y mediaciones burocráticas. Es una simple jefatura debajo de la dirección del Museo Nacional de Historia, gracias a una absurda fusión administrativa que no ha tomado en cuenta las diferencias en las gestiones debido al número, diversidad y características físicas e intelectuales de las colecciones en cada museo.

El cargo de confianza en la dirección del museo no garantiza la colocación de profesionales capaces de entender, cuando asumen las decisiones propias de su gestión, los principios, las diversas situaciones, actividades y acciones en las áreas interrelacionadas para conservar, investigar, interpretar, representar y explicar las creaciones culturales del ancestral poblador, quien interactuó con su medio social y geográfico durante un extendido y continuo proceso histórico. Esta continuidad histórica brinda a cualquier profesional competente encargado de un museo arqueológico moderno en un país andino, como el nuestro, el reto de conceptuar el mensaje enlazando a los habitantes del presente con los del pasado, a fin de hacerlos conscientes de su personalidad y potencialidades ese reforzamiento del sentido de pertenencia que consigna la Declaratoria de Xochimilco, 1998 para enfrentarse enhiestos, inquebrantables, selectivos y creativos a las circunstancias de un avance global mundial del mercantilismo neoliberal uniformador, voraz y avasallador.

Disolver para usar un término de modaconstantemente a los directores de confianza, de acuerdo con los vaivenes de los cambios políticos, I empobrece cada vez más el patrimonio arqueológico. Las tareas permanentes de preservación y conservación sufren trastornos, y "a río revuelto...", mejor dicho, "a museo revuelto, cosecha de depredadores".

La transferencia de la dirección de una institución que custodia los bienes culturales patrimoniales de una nación, que pertenecen a la historia de los pueblos y de la humanidad, debe hacerse como corresponde a sus elevados fines: sin sobresaltos, de manera regular, documentada y sustentando lo que se deja y se recibe. Si no es así, ¿a quién hacemos responsable del empobrecimiento de nuestro legado?, ¿al presidente de la República?, ¿al ministro de Educación?, ¿al director del Instituto $\mathrm{Na}$ cional de Cultura?, ¿al director saliente o entrante del museo?, ¿a cuál de ellos?

Al final, por ignorancia, indiferencia o consentimiento gratuito e intencionado, somos responsables de una situación que debe cambiar de inmediato. Después de todo, no hay tantos profesionales nacionales calificados para el puesto y menos vinculados a un gobierno en particular. Recordemos, enseñemos y aprendamos que una actitud técnico-científica sólo responde al conocimiento veraz puesto al servicio de la sociedad y nunca a autoridad o persona alguna, por más poderosa que ésta sea.

La propuesta de capacitar profesionales para que administren el patrimonio arqueológico fracasará si no se reforma sustantiva y acertadamente la política cultural del Estado, que debe ser coherente y bien llevada mediante las instituciones y las normas legales.

La Ley $N^{\circ} 6634$, que hasta 1985 defendía el patrimonio arqueológico y de cuya bondad 
Bonavía se expresara como "una ley que puede resistir una comparación con la legislación de cualquier país del mundo", para lo cual es "necesario solamente cambiar algunos artículos, modificar otros y adecuarlos a los tiempos", ha sido reemplazada por otra mal denominada Ley General de Amparo al Patrimonio Cultural de la Nación. Que sepamos, ningún arqueólogo fue convocado ni participó en su elaboración. Es una norma que fomenta la depredación, beneficia los intereses privados y soslaya la competencia técnico profesional en la administración de los bienes patrimoniales arqueológicos. Por consiguiente, nos aunamos al movimiento que exige su derogatoria.

El departamento encargado de defender y conservar los monumentos arqueológicos funciona como un apéndice del Instituto Nacional de Cultura, organismo gubernamental que se ocupa, entre otras cosas, del patrimonio histórico y artístico (colonial y republicano), el ballet, el teatro, la orquesta sinfónica y los museos.

La magnitud y la riqueza del legado arqueológico, la exigencia de un manejo y una gestión competentes para su preservación y uso social, frente a su acelerado deterioro y destrucción, justifican la creación de un organismo estatal autónomo que por ley, reglamento y código de ética profesional de sus miembros colegiados tenga la responsabilidad y la capacidad de administrar técnica y científicamente ese patrimonio. Mientras subsista como un apéndice burocrático inestable, sin autoridad de ningún tipo y carente de suficiencia técnica y medios económicos operativos, nuestra herencia arqueológica continuará empobreciéndose.

La destrucción es incalculable y sin control. Esa es la triste realidad.

Hace tiempo, cuando terminamos de redactar el documento con las propuestas presentadas sucintamente aquí, advertimos:

Las reformas planteadas deben producirse ahora, mañana será demasiado tarde. Para entonces ya habremos despojado al pueblo peruano parafraseando lo dicho por los colegas del Instituto Andino de Estudios Arqueológicos (Indea)- de lo que tal vez es su única propiedad: su identidad nacional.
Gracias a todos por acompañarme en este acto académico. A mi amigo y colega, doctor Luis Lumbreras, gracias por sus palabras en el discurso de orden.
Rosa Fung Pineda
Profesora Emérita
Universidad Nacional
Mayor de San Marcos
Lima, Perú 